Research article

Open Access

\title{
Biotransformation of Artemisinin Mediated through Fungal Strains for Obtaining Derivatives with Novel Activities
}

\author{
Suchita Srivastava ${ }^{1}$, Suaib Luqman ${ }^{1}$, Atiya Fatima ${ }^{2}$, \\ Mahendra P. DAROKAR ${ }^{*}{ }^{1}$, Arvind S. NEGI ${ }^{2}$, J. K. KUMAR ${ }^{2}$, K. SHANKER ${ }^{2}$, \\ Chandan S. ChanotiYa ${ }^{2}$, Sudeep TANDON ${ }^{3}$, Suman P. S. KHANUJA ${ }^{1}$ \\ ${ }^{1}$ Genetic Resources and Biotechnology Division, Central Institute of Medicinal and Aromatic Plants (Council \\ of Scientific and Industrial Research), Lucknow-226015, India. \\ ${ }^{2}$ Analytical Chemistry Division, Central Institute of Medicinal and Aromatic Plants (Council of Scientific and \\ Industrial Research), Lucknow-226015, India. \\ ${ }^{3}$ Process and Product Development (Industrial Technology Centre), Central Institute of Medicinal and \\ Aromatic Plants (Council of Scientific and Industrial Research), Lucknow-226015, India.
}

* Corresponding author. E-mail: mpdarokar@yahoo.com (M. P. Darokar)

Sci Pharm. 2009; 77: 87-95

doi:10.3797/scipharm.0803-15

Published: $\quad$ January $8^{\text {th }} 2009$

Accepted: January $7^{\text {th }} 2009$

Received: $\quad$ March $19^{\text {th }} 2008$

This article is available from: http://dx.doi.org/10.3797/scipharm.0803-15

(C) Srivastava et al.; licensee Österreichische Apotheker-Verlagsgesellschaft m. b. H., Vienna, Austria.

This is an Open Access article distributed under the terms of the Creative Commons Attribution License (http://creativecommons.org/licenses/by/3.0/), which permits unrestricted use, distribution, and reproduction in any medium, provided the original work is properly cited.

\begin{abstract}
Artemisinin, a sesquiterpene lactone, is the active antimalarial constituent of Artemisia annua. Several fungal strains Saccharomyces cerevisiae, Aspergillus flavus, Aspergillus niger and Picchia pastoris were used to biotransform artemisinin. Among these strains, $A$. flavus was the only microorganism capable of transforming artemisinin to deoxyartemisinin in higher yields than the previous reports. The structure of deoxyartemisinin was elucidated by spectroscopy. Deoxyartemisinin showed antibacterial activity against Staphylococcus aureus, S. epidermidis and $S$. mutans at a minimum inhibitory concentration (MIC) of $1 \mathrm{mg} / \mathrm{mL}$ compared to artemisinin whose MIC was $>2$ $\mathrm{mg} / \mathrm{mL}$.
\end{abstract}

\section{Keywords}

Biotransformation • Artemisinin • Deoxyartemisinin • Aspergillus flavus • Antibacterial 


\section{Introduction}

Artemisinin, a sesquiterpene lactone isolated from the aerial parts of Artemisia annua (Family: Asteraceae) is a potent therapeutic agent combating multidrug resistant Plasmodium falciparum strains and chloroquine-resistant parasites [1, 2]. The metabolism, chemical transformation, thermal rearrangement and decomposition studies of artemisinin were well established [3,4]. Among known antimalarial compounds, artemisinin has a novel structure with a unique 1,2,4-trioxane ring system. But, the utility of artemisinin is limited in the biological systems due to its toxicity and water insolubility $[5,6]$. Studies on modification of artemisinin through biological [4, 7-8] and chemical methodologies [9, 10] have been reported [11] to yield more effective and water soluble derivatives. Studies on quantitative structure activity relationship of artemisinin suggest that the structural modification of sesquiterpene lactone may yield desirable antimalarial analogues [12-14]. Biological conversions using microorganisms and their enzymes are most effective on sesquiterpene molecules due to their susceptibility to bioconversion at a cost effective rate.

Studies on the microbial transformation of artemisinin with Nocardia corollina, Penicillium chrysogenum, Mucor polymorphus, Cunninghamella echinulata, Mucor ramannianus, Eurotium amstelodami, Streptomgillus niger, Cunninghamella elegans yielded

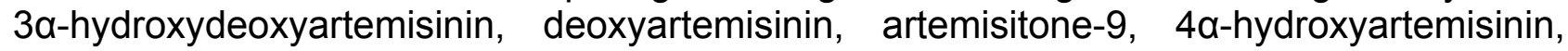

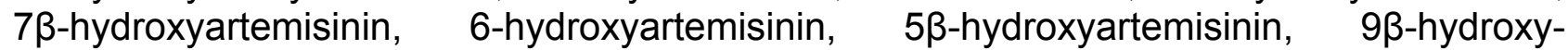

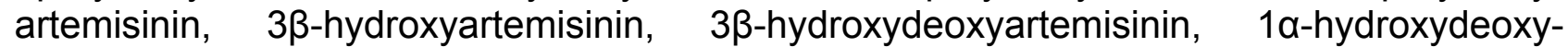

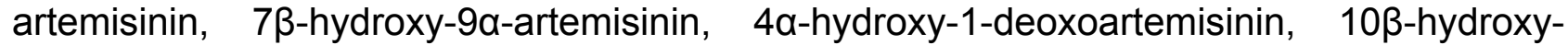
artemisinin and 3a-hydroxydeoxyartemisinin respectively [4, 15-20]. The importance and usefulness of microbial transformation in carrying out a variety of chemical conversions is well documented in the previously published reports [21, 22].

Microorganisms are one of the most efficient biocatalytic agents with ability to metabolize a wide range of substrates. Several reports on microbial transformation of sesquiterpenes have been published earlier [23-26]. Biotransformation of artemisinin usually includes the processes such as hydroxylation of methyl, methyne and methylene groups deoxidation reactions, hydration reactions and breakdown of heterocyclic rings [8, 15, 16, 19, 27-32].

In the present study we have examined the bioconversion of artemisinin using different microorganisms. A. flavus was found to transform artemisinin to deoxyartemisinin in higher yield $(30.5 \%)$ than the previous reports $[4,15,31]$. The biotransformed product was characterized by NMR, IR and Mass spectroscopy. Deoxyartemisinin was also showed antibacterial activity.

\section{Results and Discussion}

Four different fungi, Saccharomyces cerevisiae, Aspergillus flavus, Aspergillus niger and Picchia pastoris were initially screened for their ability to biotransform artemisinin. Out of these, $A$. flavus efficiently converted artemisinin to deoxyartemisinin in $48 \mathrm{~h}$ grown culture. The biotransformed product was isolated through column chromatography on silica gel. The product was identified on the basis of its melting point and spectroscopic data. In the ESI mass spectroscopy deoxyartemisinin showed molecular ion peaks at $289[\mathrm{M}+\mathrm{Na}]^{+}$, $305[\mathrm{M}+\mathrm{K}]^{+}$and $571.1[2 \mathrm{M}+\mathrm{K}]^{+}$in positive mode and at $265[\mathrm{M}-1]^{-}$in the negative ion 
mode. In the El mass spectra it showed molecular ion peak at 266 consistent with the molecular formulae $\mathrm{C}_{15} \mathrm{H}_{22} \mathrm{O}_{4}$ and further fragmentation pattern clearly indicating it as deoxyartemisinin. The compound's ${ }^{1} \mathrm{H}$ and ${ }^{13} \mathrm{C}$ NMR and different $2 \mathrm{D}$ spectral data were well in agreement with the earlier published reports [4].

Artemisinin was biotransformed to an extent of $26-32 \%$ into deoxyartemisinin which was separated through column chromatography to obtain $95 \%$ purity with a $30.50 \%$ yield. The purity was evaluated using RP-HPLC area normalization method.

Biotransformation performed by Aspergillus flavus with our protocol was much better in yield $(30.50 \%)$ than the previously reported methods [4, 15]. The compound deoxyartemisinin showed invitro antibacterial activity against Staphylococcus aureus, Staphylococcus epidermidis and Streptococcus mutans at a minimum inhibitory concentration (MIC) of $1 \mathrm{mg} / \mathrm{mL}$, whereas MIC of artemisinin was found to be more than $2 \mathrm{mg} / \mathrm{mL}$.

For the last few years, research work on artemisinin and its analogues was focused on to decipher the enzymes involved in the proposed biosynthetic pathway [35-37]. In this direction, the present study was aimed to identify the possible conversions of artemisinin using microorganisms and to explore the transformation similarities between the present microbial model and previously reported systems. Such a microbial system could then further be used as a model to predict and generate metabolites of artemisinin and its analogues for novel biological activities.

In conclusion, the formation of the deoxyartemisinin suggests that $A$. flavus has the potential to serve as a microbial model for generating metabolites of artemisinin and its related analogues of varied structural diversity. Thus, it appears that $A$. flavus may be a useful tool to prepare various metabolites of artemisinin and its related analogues. The biological activity obtained with deoxyartemisinin may provide preliminary information for the design of novel antibacterial agents.

\section{Experimental}

\section{Substrate}

Artemisinin (Fig. 1) was isolated from the leaves of Artemisia annua and characterized by melting point, NMR and Mass spectroscopy (1). Artemisinin was dissolved in sterile DMSO $(100 \mathrm{mg} / \mathrm{ml})$ to prepare a stock solution and $625 \mu \mathrm{l}$ of it was added to $125 \mathrm{ml}$ of Sabouraud Dextrose Broth (SDB) to make the final concentration of $0.5 \mathrm{mg} / \mathrm{ml}$.

\section{Microorganisms used}

The Microorganisms tested for the biotransformations were Saccharomyces cerevisiae, Aspergillus flavus, Aspergillus niger and Picchia pastoris. Among these strains, A. flavus showed promising results with the formation of a distinct product.

\section{Media preparation}

All the fermentation experiments using $A$. flavus were carried out in the defined medium of SDB comprising of Peptone (10 grams) and dextrose (40 grams) in 1 litre of distilled water. 
The $\mathrm{pH}$ was adjusted to 5.8 before autoclaving at $121^{\circ} \mathrm{C}$ for 15 minutes. Stock cultures of the fungal strains were stored on the slants of Sabouraud Dextrose Agar at $4^{\circ} \mathrm{C}$.

\section{Fermentation procedure}

The cultures of $A$. flavus were grown on Sabouraud Dextrose Agar plates at $28^{\circ} \mathrm{C}$ for a week. Well developed mycelia were removed from the plates, suspended in $10 \mathrm{ml}$ of normal saline and used to inoculate $125 \mathrm{ml}$ of SDB in a $500 \mathrm{ml}$ shaker flask. The substrate artemisinin was added to the broth at the concentration of $0.5 \mathrm{mg} / \mathrm{ml}$ at the time of inoculation. Cultures were grown for 48 hours on rotary shaker incubator (Kuhner shaker) at $28^{\circ} \mathrm{C}$ with shaking speed at $200 \mathrm{rpm}$. Culture control consisted of fermentation blank in which microorganism was grown under identical conditions except for no substrate. Substrate control consisted of sterile medium containing the same amount of substrate incubated under the same conditions.

\section{Isolation of metabolites}

The cultures were harvested by centrifugation at $10,000 \mathrm{rpm}$ for 25 minutes in centrifuge (REMI). The broth and mycelia were separated using coarse filter paper (Whatmann no.1) in a funnel. The culture broth was extracted thrice with equal volumes of ethyl acetate and evaporated under vacuum. The residue was washed with chloroform and evaporated under vacuum. The chloroform soluble portion $(980 \mathrm{mg})$ was column chromatographed (3x $50 \mathrm{~cm})$ over silica gel (60-120 mesh size). A mixture of hexane-ethyl acetate was used as eluent with increasing polarity of ethyl acetate $(2 \%, 4 \%)$ in hexane. Fractions collected in $8 \%$ ethyl acetate-hexane were checked on TLC using artemisinin spray reagent to confirm deoxyartemisinin developed in green color. These fractions were evaporated in vacuum and the residue was recrystallised with chloroform-hexane $(1: 3)$ to get deoxyartemisinin (Fig. 2) as a colorless solid. Compound 2 (Yield $=282 \mathrm{mg}(30.5 \%)$ m.p. $=111-112^{\circ} \mathrm{C}$ ) showed IR (KBr): 2938, 1748, 1389, 1139, $1016 \mathrm{~cm}^{-1}$; EI MS (MeOH): 266 [M+1, 237, 224, 195, 165, 164. ESI MS (MeOH): Positive mode: 289 [M+Na] $^{+}, 305[\mathrm{M}+\mathrm{K}]^{+}, 571.1[2 \mathrm{M}+\mathrm{K}]^{+}$; Negative mode: 265 [M-1] ${ }^{-}$. NMR data given in Table 1. The purity of (2) was obtained using peak area normalization of high performance liquid chromatographic analysis method [column- Phenomenex $\mathrm{C}_{18} 4.6$ x 250mm, $5 \mu \mathrm{m}$; mobile phase- acetonitrile: $\mathrm{CH}_{3} \mathrm{COONH}_{4}(10 \mathrm{mM})+0.1 \% \mathrm{HCOOH}$ (85:15); Flow- 1mL/min; detection-210nm PDA].

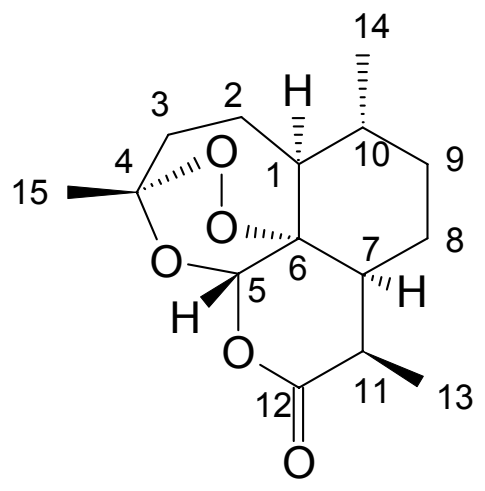

Fig. 1. Artemisinin 


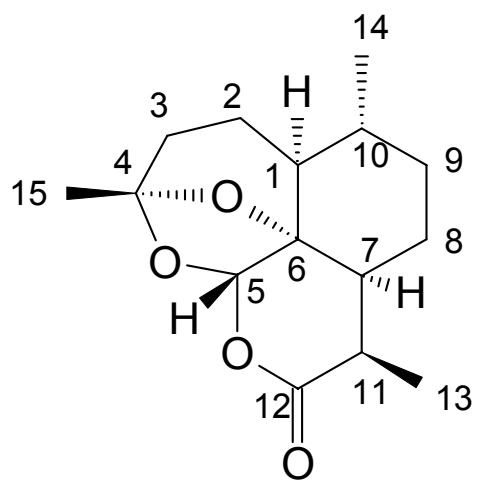

Fig. 2. Deoxyartemisinin

\section{Characterization of transformed products}

Tab. 1. ${ }^{1} \mathrm{H}$ and ${ }^{13} \mathrm{CNMR}$ data of 1 and 2 (both in $\mathrm{CDCl}_{3}, \delta$ values) ${ }^{\mathrm{a}, \mathrm{b}}$

\begin{tabular}{|c|c|c|c|c|}
\hline \multirow[t]{2}{*}{ Assignment } & \multicolumn{2}{|c|}{ Artemisinin (1) } & \multicolumn{2}{|c|}{ Deoxyartemisinin (2) } \\
\hline & ${ }^{13} \mathrm{C}$ & ${ }^{1} \mathrm{H}$ & ${ }^{13} \mathrm{C}$ & 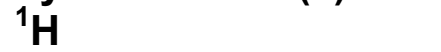 \\
\hline 1 & 50.17 & $1.40(\mathrm{~m})$ & 45.10 & $1.27(\mathrm{~m})$ \\
\hline 2 & 24.87 & $\begin{array}{l}1.47(\mathrm{~m}), \\
2.03(\mathrm{~m})\end{array}$ & 22.43 & $\begin{array}{l}1.23(\mathrm{~m}), \\
188(\mathrm{~m})\end{array}$ \\
\hline 3 & 35.96 & $\begin{array}{l}2.43 \text { (ddd), } \\
2.07 \text { (ddd) }\end{array}$ & 34.41 & $\begin{array}{l}1.59(\mathrm{~m}) \\
1.77(\mathrm{~m})\end{array}$ \\
\hline 4 & 105.32 & - & 109.51 & - \\
\hline 5 & 93.68 & $5.87(\mathrm{~s})$ & 100.01 & $5.88(\mathrm{~s})$ \\
\hline 6 & 79.48 & - & 82.80 & \\
\hline 7 & 45.05 & $1.77(\mathrm{~m})$ & 42.88 & $2.44(\mathrm{dt})$ \\
\hline 8 & 23.39 & $\begin{array}{l}1.88(\mathrm{~m}) \\
1.12(\mathrm{~m})\end{array}$ & 23.90 & $\begin{array}{l}1.07(\mathrm{~m}) \\
1.88(\mathrm{~m})\end{array}$ \\
\hline 9 & 33.66 & $\begin{array}{l}1.81(\mathrm{~m}) \\
1.09(\mathrm{~m})\end{array}$ & 33.91 & $\begin{array}{l}1.11(\mathrm{~m}) \\
1.77(\mathrm{~m})\end{array}$ \\
\hline 10 & 37.63 & $1.43(\mathrm{~m})$ & 35.75 & $1.24(\mathrm{~m})$ \\
\hline 11 & 32.89 & $3.38-3.42(q d)$ & 33.13 & 3.39 (distorted quartet) \\
\hline 12 & 171.82 & - & 171.97 & - \\
\hline 13 & 12.49 & $1.23(\mathrm{~d}, 7.2 \mathrm{~Hz})$ & 12.93 & $1.21(\mathrm{~d}, 7.2 \mathrm{~Hz})$ \\
\hline 14 & 19.74 & $0.99(\mathrm{~d}, 6.0 \mathrm{~Hz})$ & 18.87 & $1.01(\mathrm{~d}, \mathrm{~J}=6.0 \mathrm{~Hz})$ \\
\hline 15 & 25.15 & $1.46(\mathrm{~s})$ & 24.28 & $1.46(\mathrm{~s})$ \\
\hline
\end{tabular}

Melting points were determined using Toshniwal melting point apparatus and were uncorrected. Biotransformation reactions were monitored on Merck aluminium thin layer chromatography (TLC) plates. Visualisation was accomplished by dipping TLC plates with artemisinin reagent (Glacial acetic acid: Sulphuric acid: Anisaldehyde, 500:10:5) and charring them at higher temperatures. Column chromatography was carried out on silica gel (60-120 mesh, Thomas Baker Chemicals). ${ }^{1} \mathrm{H}$ NMR and ${ }^{13} \mathrm{CNMR}$ analysis was 
performed on Bruker Avance-300 MHz spectrometer using tetramethylsilane as internal standard. Chemical shifts are given in $\delta$ ppm values (Table 1). Electron impact ionization (EI) mass spectra were recorded on Perkin Elmer GC-MS system after dissolving the compounds in methanol. Electrospray ionization (ESI) mass was recorded on Shimadzu LC-MS system in both positive and negative modes after dissolving compound in methanol.

\section{Biological activity}

Antibacterial activity (Table 2 ) of artemisinin and deoxyartemisinin were performed as per standardized protocols [33, 34].

Tab. 2. Minimum inhibitory concentration (MIC) of artemisinin and deoxyartemisinin against Staphylococcus aureus, Staphylococcus epidermidis and Streptococcus mutans.

\begin{tabular}{lll}
\hline Pathogenic Bacteria & $\begin{array}{l}\text { Minimum Inhibitory } \\
\text { Artemisinin }\end{array}$ & $\begin{array}{c}\text { Concentration }(\mathbf{m g} / \mathbf{m l}) \\
\text { Deoxyartemisinin }\end{array}$ \\
\cline { 2 - 3 } Staphylococcus aureus & $>2$ & 1 \\
Staphylococcus epidermidis & $>2$ & 1 \\
Streptococcus mutans & $>2$ & 1
\end{tabular}

\section{Acknowledgement}

Authors are grateful to Council of Scientific and Industrial Research, New Delhi for financial assistance and support.

\section{Authors' Statement}

\section{Competing Interests}

The authors declare no conflict of interest.

\section{References}

[1] Klayman DL.

Qinghaosu (artemisinin): an antimalarial drug from China.

Science. 1985; 228: 1049-1055.

doi:10.1126/science.3887571

[2] Liu C, Zhao Y, Wang Y.

Artemisinin: current state and perspectives for biotechnological production of an antimalarial drug.

Appl Microbiol Biotechnol. 2006; 72: 11-20.

doi:10.1007/s00253-006-0452-0

[3] Lin AJ, Klayman DL, Hoch JM, Silverton JV, George CF.

Thermal Rearrangement and Decomposition Products of Artemisinin (Qinghaosu).

J Org Chem. 1985; 50: 4504-4508.

doi:10.1021/jo00223a017 
[4] Lee IS, El-Sohly HN, Croom EM, Hufford CD.

Microbial metabolism studies of the antimalarial sesquiterpene artemisinin.

J Nat Prod 1989; 52: 337-341.

doi:10.1021/np50062a020

[5] Webster HK, Lehnert EK.

Chemistry of artemisinin: an overview.

Trans R Soc Trop Med Hyg. 1994; 88: 27-S29.

doi:10.1016/0035-9203(94)90467-7

[6] Meshnick SR, Taylor TE, Kamchonwongpaisan S.

Artemisinin and the antimalarial endoperoxides: From herbal remedy to targeted chemotherapy.

Microbiol Rev. 1996; 60: 301-315.

PMid:8801435

[7] Hufford CD, Khalifa SI, Orabi KY, Wiggers FT.

$1 \alpha$-Hydroxyarteether, a new microbial transformation product.

J Nat Prod. 1995; 58: 751-755.

doi:10.1021/np50119a016

[8] Orabia KA, Galala AM, Abdel-Rahim S Ibrahima, Farouk S El-Feralya, Sherief I Khalifab, Hala N El-

Sohlyc.

Microbial metabolism of artemisitene.

Phytochemistry. 1999; 51: 257-261.

doi:10.1016/S0031-9422(98)00770-5

[9] Sy L, Hui S, Cheung K, Brown, GD.

A rearranged hydroperoxide from the reduction of artemisinin.

Tetrahedron. 1997; 53: 7493-7500.

doi:10.1016/S0040-4020(97)00444-4

[10] El-Feraly FS, Al-Meshal IA, Al-Yahya MA, Hifnawy MS.

On the possible role of qinghaoacid in the biosynthesis of artemisinin.

Phytochemistry. 1986; 25: 2777-2778.

doi:10.1016/S0031-9422(00)83739-5

[11] Begue JP, Bonnet DD.

The future of antimalarials: artemisinins and synthetic endoperoxides.

Drugs Future. 2005; 30: 509-518.

doi:10.1358/dof.2005.030.05.901987

[12] Avery MA, Alvim-Gaston M, Woolfrey JR.

Synthesis and structure-activity relationships of peroxidic antimalarials based on artemisinin.

Adv Med Chem. 1999; 4: 125-217.

doi:10.1016/S1067-5698(99)80005-4

[13] Parshikov IA, Miriyala B, Muraleedharan KM, Illendula A, Avery MA, Williamson JS.

Biocatalysis of the Antimalarial Artemisinin by Mucor ramannianus strains.

Pharm Biol. 2005; 43: 579-582.

doi:10.1080/13880200500301597

[14] Parshikov IA, Muraleedharan KM, Miriyala B, Avery MA, Williamson JS.

Microbial transformation of artemisinin to 5-hydroxyartemisinin by Eurotium amstelodami and

Aspergillus niger.

J Ind Microbiol Biotechnol. 2006; 33: 349-352.

doi:10.1007/s10295-005-0071-2

[15] Zhan J, Guo H, Dai J, Zhang Y, Guo D.

Microbial transformation of artemisinin by Cunninghamella echinulata and Aspergillus niger.

Tetrahedron Lett. 2002; 43: 4519-452.

doi:10.1016/S0040-4039(02)00812-2 
[16] Zhan J, Zhang Y, Guo H, Han J, Ning L, Guo D.

Microbial metabolism of artemisinin by Mucor polymophosporus and Aspergillus niger.

J Nat Prod 2002; 65: 1693-1695.

doi:10.1021/np020113r

[17] Parshikov IA, Muraleedharan KM, Avery MA, Williamson JS.

Transformation of artemisinin by Cunninghamella elegans.

Appl Microbiol Biotechnol. 2004; 64: 782-786.

doi:10.1007/s00253-003-1524-z

[18] Parshikov IA, Muraleedharan KM, Miriyala B, Avery MA, Williamson JS.

Hydoxylation of Deoxoartemisinin by Cunninghamella elegans.

J Nat Prod 2004; 67: 1595-1597.

doi:10.1021/np040089c

[19] Parshikov IA, Muraleedharan K M, Miriyala B, Avery MA, Williamson JS.

Hydroxylation of 10-deoxoartemisinin to 15-hydroxy-10-deoxoartemisinin by Aspergillus niger.

Biotechnol Lett. 2004; 26: 607-610.

doi:10.1023/B:BILE.0000021965.55420.e9

[20] Liu JH, Chen YG, Yu BY, Chen YJ.

A novel ketone derivative of artemisinin biotransformed by Streptomyces griseus ATCC 13273.

Bioorg Med Chem Lett. 2006; 16: 1909-1912.

doi:10.1016/j.bmcl.2005.12.076

[21] Venisetty RK, Ciddi V.

Application of microbial biotransformation for the new drug discovery using natural drugs as substrates.

Curr Pharm Biotechnol. 2003; 4: 153-67.

doi:10.2174/1389201033489847

[22] García-Granados A, Liñán E, Martínez A, Onorato ME, Parra A, AriasJM.

Synthesis of enantio-manoyl oxides: modifiers of the activity of adenylatecyclase enzyme.

Phytochemistry. 1995; 38: 287-93.

doi:10.1016/0031-9422(94)00549-9

[23] Hikino H, Tokuoka Y, Hikino Y, Takemoto T.

Microbial transformation of $\alpha$-kessyl alcohol to kessyl glycol and kessane-2 $\beta, 7-d i o l$.

Tetrahedron. 1968; 24: 3147-3152.

doi:10.1016/S0040-4020(01)98721-6

[24] Hikino H, Aota K, Tokuoka Y, Takemoto T.

Biochemical synthesis. II. Microbial transformation of cyperotundone to eugenol and isopatchoul-4-en-

3-on-8-alpha-ol.

Chem Pharm Bull. 1968; 16: 1088-1090.

PMid:5710071

[25] Clark AM, Hufford CD.

Microbial transformations of the sesquiterpene lactone costunolide

J Chem Soc Perkin Trans. 1979; 1: 3022.

doi:10.1039/P19790003022

[26] Elmarakby SA, Clark AM, Baker JK, Hufford CD.

Microbial metabolism of bornaprine, 3-(diethylamino)propyl 2-phenylbicyclo[2.2.1]heptane-2-

carboxylate.

J Pharm Sci. 1986; 75: 614-618.

doi:10.1002/jps.2600750620

[27] Hufford CD, Lee IS, El-Sohly HN, Chi HT, Baker JK.

Structure elucidation and thermospray high-performance liquid chromatography/mass spectroscopy

(HPLC/MS) of the microbial and mammalian metabolites of the antimalarial arteether.

Pharm Res. 1990; 7: 923-927.

doi:10.1023/A:1015993722846 
[28] Lee IS, Hufford CD.

Metabolism of antimalarial sesquiterpene lactones.

Pharmacol Ther. 1990; 48: 345-355.

doi:10.1016/0163-7258(90)90053-5

[29] Ziffer H, Hu Y, Pu Y.

Beauveria sulfurescens mediated oxidation of dihydroartemisinin derivatives.

NATO ASI Ser C Math Phys Sci. 1992; 381: 361-373.

[30] Abourashed EA, Hufford CD.

Microbial transformation of artemether.

J Nat Prod. 1996; 59: 251-253.

doi:10.1021/np960060b

[31] Grogan GJ, Holland HL.

The biocatalytic reactions of Beauveria spp.

J Mol Catal B. 2000; 9: 1-32.

doi:10.1023/A:1015516929682

[32] Fiaux de Medeiros S, Avery MA, Avery B, Leite SGF, Freitas ACC, Williamson JS.

Biotransformation of 10 -deoxoartemisinin to its $7 \beta$-hydroxy derivative by Mucor ramannianus.

Biotechnol Lett. 2002; 24: 937-941.

doi:10.1016/0002-9343(65)90096-3

[33] Petersdorf RG, Sherris JC.

Methods and significance of in vitro testing of bacterial sensitivity to drugs.

Am J Med. 1965; 39: 766-779.

doi:10.1016/0002-9343(65)90096-3

[34] Murray PR, Barone EJ, P Faller MA, Tenover FC, Yolken RH, editors.

Jorgensson JH, Turnigde DJ, Washington JA.

Antibacterial susceptibility tests: Dilution and disc diffusion methods.

In: Manual of Clinical Microbiology, $7^{\text {th }}$ Edn.

The American Society of Microbiology Press: Washington DC, 1999: 1526-1543.

[35] Bouwmeester HJ, Wallaart TE, Janssen MHA, Loo BV, Jansen BJM, Posthumus MA, Schmidt CO, Kraker JD, Konig WA, Franssen MCR.

Amorpha 4,11-diene synthase catalyses the first probable step in artemisinin biosynthesis.

Phytochemistry. 1999; 52: 843-854.

doi:10.1016/S0031-9422(99)00206-X

[36] Wallaart TE, van Uden W, Lubberink HG, Woerdenbag HJ, Pras N, Quax WJ.

Isolation \& identification of dihydroartemisincic acid from Artemisia annua \& its possible role in the biosynthesis of artemisinin.

J Nat Prod. 1999; 62: 430-433.

doi:10.1021/np980370p

[37] Bertea CM, Freije JR, Vander Woude H, Verstappen FWA, Perk L, Marquez V. De Kraker JW, Posthumus MA, Jansen BJM, de Groot A Franssen MCR, Bouweester HJ.

Identification of intermediates \& enzymes involved in the early steps of artemisinin biosynthesis in $A$ annua.

Planta Med. 2005; 71: 40-47.

doi:10.1055/s-2005-837749 